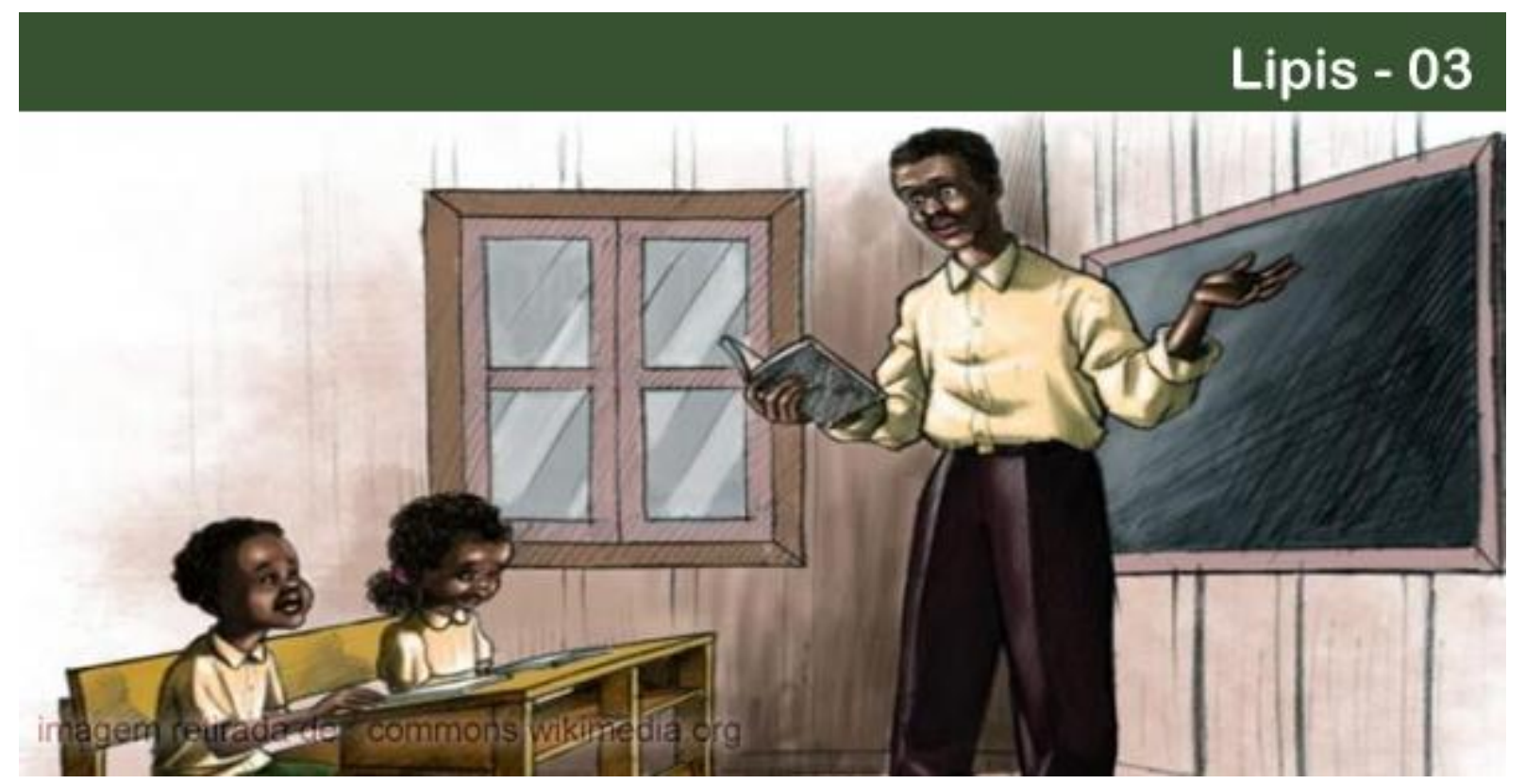

\title{
PEDAGOGIA DE PROJETO E AQUISIÇÃO DA SEGUNDA LÍNGUA ATRAVÉS DO USO DO DIÁRIO NO ENSINO FUNDAMENTAL ${ }^{1}$
}

\author{
Assane Diakhate \\ Doutor em Ciências da Educação. Professor e pesquisador na UFR, em Saint-Louis, Senegal. Diretor adjunto do \\ UFR SEFS. E-mail: assane.diakhate@ugb.edu.sn.
}

\section{Pape Meïssa Coulibaly}

Especialista em Tecnologias da Informação e Comunicação para o Ensino (TICE) e didática do inglês. Coordenador da certificação on-line em administração escolar da UFR SEFS. E-mail: papemeissa.coulibaly@ugb.edu.sn.

\section{Efua Irène Amenyah}

Doutora em Ciências Psicológicas e Educação. Professora e pesquisadora na Universidade Gaston Berger (UGB), em Saint-Louis, Senegal. E-mail: efua-irene.amenyah@ugb.edu.sn.

Resumo: Este artigo trata da questão dos métodos de ensino e dispositivos pedagógicos implementados nas escolas de ensino fundamental do Senegal. A reflexão enfoca a Pedagogia de Projeto e o uso do diário no ensinoaprendizagem. Neste estudo, questionou-se um elemento importante do sistema educacional: o diário mantido pelos alunos durante a realização do projeto em torno do qual as atividades de ensino-aprendizagem são articuladas. Assim, os questionamentos giram em torno de como esse elemento do dispositivo pode contribuir para a aquisição do francês, o que caracteriza esse elemento e a maneira como é usado pelos alunos. A pedagogia do projeto faz parte das teorias de aprendizagem sócio-construtivistas na educação. No centro do sistema está o projeto cujos autores-atores são estudantes. Embora sabendo que diferentes aspectos do sistema permitem a integração de vários fatores que influenciam a aquisição da linguagem (Klein, 1989), as perguntas que estamos tentando responder girarão em torno de como essa ferramenta específica pode contribuir para a aquisição da língua francesa, o que a caracteriza e como é usada pelos alunos. Em relação ao estudo, foi realizada uma observação participante durante a implementação do dispositivo de pedagogia de projeto em uma escola primária em Dakar, Senegal. Os

\footnotetext{
${ }^{1}$ Tradução de: Lúcia Ozório (Laboratório Experice, França - universidades Paris 8 e Paris 13-Nord; Laboratório Lipis - Pontifícia Universidade Católica - PUC-RJ).
}

\section{POLÊM!CA | LABORE (3:}

Polêmica - Revista Eletrônica da Uerj - Rua São Francisco Xavier, 524, $1^{\circ}$ andar bloco D, sl.1001 • Tels.: +55 21 2334-4088 / 4087 • http://www.e-publicacoes.uerj.br/index.php/polemica/index http://www.labore.uerj.br • laboreuerj@yahoo.com.br 
dados foram coletados através de observação direta, entrevistas e anotações em diários de estudantes que produziram resultados significativos em muitas questões. Através do experimento, os diários de estudantes provaram ser eficazes nas atividades de ensino e aprendizagem e na aquisição do francês como segunda língua, permitindo não apenas uma pedagogia ativa, mas também promovendo a liberdade de expressão entre os alunos. Com os diários dos estudantes e suas características, os alunos gradualmente produziram textos que atestam a aquisição de habilidades lingüísticas situadas e sua necessidade de expressar suas preocupações. Os resultados também mostraram a importância dos diários dos alunos como ferramenta eficaz para o professor na estratégia de sala de aula.

Palavras-chave: Atividades de ensino-aprendizagem. Aquisição da língua. Pedagogia de Projeto. Diário do aluno.

\title{
PROJECT PEDAGOGY AND ACQUISITION OF SECOND LANGUAGE BY THE USE OF THE LOGBOOK AT ELEMENTARY SCHOOL
}

\begin{abstract}
This article deals with the issue of teaching methods and pedagogical tools implemented on elementary schools in Senegal. It focuses on the pedagogy project and the use of student journals in teaching and learning activities. The study questions an important aspect of pedagogical tool: student journals, kept by pupils while working on their project around which teaching and learning activities are centered. Therefore, questions we are trying to answer will revolve how that specific tool can contribute to the acquisition of French language, what characterizes it and how it is used by the pupils. Pedagogy Project is part of socio-constructivist learning theories in education. At the center of the system lies the project whose authors-actors are students. While knowing that different aspects of the system allow the integration of various factors influencing language acquisition (Klein, 1989), the questions we are trying to answer will revolve around how this particular tool can contribute to French language acquisition, which means characterizes it and how it is used by students. To conduct our study, we proceeded by participative observation while implementing project pedagogy system in elementary school in Dakar, Senegal. Data were collected through direct observation, interviews and notes on student journals have produced significant results on many issues. Through the experiment, student journals have proved to be effective on teaching and learning activities and acquisition of French as second language by allowing not only an active pedagogy, but also by promoting freedom of expression among pupils. With student journals and its characteristics, pupils have gradually produced texts that attest situated language skills acquisition and their need to express their concerns. Results have also shown the importance of student journals as effective tool for the teacher in classroom strategy.
\end{abstract}

Keywords: Teaching and learning activities. Language acquisition. Pedagogy Project. Student journals.

\section{Introdução}

O nível dos estudantes em geral e, particularmente, em francês, no Senegal, tem sido frequentemente objeto de debates e controvérsias (FALL, 2003). Independente da posição adotada, é fácil constatar a dificuldade de muitos alunos, tanto a nível oral como a nível escrito. Suas expressões em diferentes contextos revelam problemas de gerir $^{2}$ a língua francesa, seja como língua oficial ou segunda língua. De fato, muitos professores se queixam de erros de gramática, ortografia, conjugação, sintaxe etc. nas produções orais e escritas dos alunos.

Essa dificuldade (baixa de nível) levanta uma série de questões relacionadas às causas do fenômeno: os alunos são simplesmente fracos? Ou os métodos de ensino devem ser questionados? Couëdel e Blondeau (2002) parecem confirmar a segunda hipótese; de acordo

\footnotetext{
${ }^{2}$ Ter um domínio satisfatório da língua francesa.

\section{POLÊM!CA | LABORE (I:}

Polêmica - Revista Eletrônica da Uerj - Rua São Francisco Xavier, 524, $1^{\circ}$ andar bloco D, sl.1001 • Tels.: +55 21 2334-4088 / 4087 • http://www.e-publicacoes.uerj.br/index.php/polemica/index http://www.labore.uerj.br • laboreuerj@yahoo.com.br
} 
com os autores, para uma melhor aquisição de uma língua estrangeira e, principalmente, do francês, é preciso ir além das estruturas formais existentes.

Portanto, trata-se de pesquisar e utilizar novos dispositivos pedagógicos. Nessa perspectiva, Couëdel (2007) utilizou o dispositivo de formação de professores, que faz parte de uma pesquisa-ação envolvendo vários atores, principalmente professores e alunos. Em outras palavras, é uma questão de estudar os processos de aquisição da língua, fazendo um ir e vir perpétuo entre a teoria e a prática.

Segundo Couëdel e Blondeau (2002), o dispositivo de aquisição difere do "fingir estar junto" da pedagogia tradicional, caracterizada pelas aprendizagens individuais, normatizadas, padronizadas e por um espírito competitivo. O projeto coletivo que suscita criatividade, iniciativa, desenvolvimento do espírito crítico e leva à inserção social do sujeito, condição sine qua non $^{3}$ para seu sucesso acadêmico, é central para este dispositivo. O professor desempenha o papel de facilitador e de pessoa inspiradora no processo, acompanhando os alunos - os participantes na realização do projeto de que são autores-atores.

Neste artigo questiona-se um elemento central do dispositivo: o diário que deve ser mantido pelos alunos durante a realização do projeto em torno do qual as atividades de ensinoaprendizagem são articuladas. Assim, as problematizações aqui giram em torno dos seguintes questionamentos: como esse elemento do dispositivo - o diário - pode contribuir favoravelmente para a aquisição do francês? O que o caracteriza? Como os alunos lidam com essa nova disposição? Portanto, é necessário apontar teorias que permitam pensar a maneira de conseguir adquirir a língua.

\section{Dispositivo de Pedagogia de Projeto e teorias de aprendizagem de uma língua}

Nos seus trabalhos, Klein (1989) insiste sobre os diferentes fatores que entram em jogo no processo de aquisição de uma língua:

\footnotetext{
Identificamos três componentes necessários para qualquer aprendizado de uma língua: disposição para aprender, capacidade linguística e acesso à língua. Cada um desses componentes pode se apresentar de maneira muito diferente, dependendo do caso. A disposição para aprender pode ser muito diferente do que ela como neste exemplo (quando você aprendeu inglês, as forças que o estimularam a aprender eram de uma natureza bastante diferente). A capacidade linguística pode mudar drasticamente ao longo da vida - positivamente, porque sabemos mais coisas na idade adulta, ou negativamente, por exemplo, porque a memória ou a audição regridem. $\mathrm{O}$ acesso à
}

\footnotetext{
${ }^{3}$ Expressão latina, sinônimo de fundamental, indispensável, essencial.

\section{POLÊM!CA $\mid$ LABORE}

Polêmica - Revista Eletrônica da Uerj - Rua São Francisco Xavier, 524, $1^{\circ}$ andar bloco D, sl.1001 • Tels.: +55 21 2334-4088 / 4087 • http://www.e-publicacoes.uerj.br/index.php/polemica/index http://www.labore.uerj.br • laboreuerj@yahoo.com.br
} 
língua não é necessariamente feito por meio de comunicação real ou tentativas de comunicação, como por exemplo, ele pode ser muito indireto e restrito, como no ensino do latim. Mas cada um desses componentes deve estar presente de uma forma ou de outra (KLEIN, 1989, p. 25).

Com base nos trabalhos de Klein (1989), para a aquisição de uma língua, o dispositivo de Pedagogia de Projeto afirma certa ancoragem nas teorias de aprendizagem socioconstrutivistas de Vygotsky (1997). Para utilizar o dispositivo de Pedagogia de Projeto, se faz necessário partir das teorias de aprendizagem que subentendem a aquisição de uma língua. Assim, um recorte foi estabelecido entre as três teorias conhecidas até agora: as teorias mecanicistas, as teorias mentalistas e as teorias construtivistas com duas abordagens: uma de Piaget (1966), que se considera puramente construtivista, e a socioconstrutivista, de Vygotsky.

Nas teorias mecanicistas, principalmente com o behaviorismo (SKINNER, 1957), a aquisição da linguagem se faz segundo uma concepção própria daquele que fala, como em seu princípio de condicionamento, no qual o falante é considerado um objeto transformável. Essas teorias consideram que

a aprendizagem da língua era muito semelhante à aprendizagem de sílabas sem significação, exceto no caso de uma criança, auxiliada pela imitação, que ao imitar o exemplo de um "modelo" é encorajada após a obtenção do desempenho correto. Havia uma insistência maior nas palavras que na gramática. Como resultado, essa abordagem perdeu completamente as possibilidades combinatórias e geradoras inerentes a uma sintaxe que permite à criança construir frases que ela nunca ouviu antes e que ela não pode imitar, porque estas frases não existem na linguagem adulta (BRUNER, 1983, p. 37).

No oposto às teorias mecanicistas, as mentalistas dão grande importância ao lugar ocupado pelo falante na aquisição da língua, considerando-o como um sujeito pensante. Por exemplo, Chomsky (2011) fornece trabalhos que baseiam-se no "caráter natural" da aquisição da primeira língua e na existência de habilidades inatas, específicas à espécie humana e à aprendizagem línguística. Assim, é inata a capacidade dos seres humanos disporem de uma gramática universal da qual depende a aquisição da estrutura da língua (CHOMSKY, 2011).

Na mesma linha de Chomsky, Pit Corder (1980) apresenta pesquisas orientadas para o estudo dos erros dos alunos com o objetivo de ajudá-los a melhorar suas habilidades e criar condições favoráveis para a aprendizagem da língua (referência). Deve-se lembrar, no entanto, que, mais tarde, Pit Corder abandonou essa hipótese para se juntar a Krashen (1981), cuja metodologia é baseada na oposição entre as noções de aprendizagem e de aquisição (KRASHEN, 1981).

\section{POLÊM!CA | LABORE}

Polêmica - Revista Eletrônica da Uerj - Rua São Francisco Xavier, 524, $1^{\circ}$ andar bloco D, sl.1001 • Tels.: +55 21 2334-4088 / 4087 • http://www.e-publicacoes.uerj.br/index.php/polemica/index http://www.labore.uerj.br • laboreuerj@yahoo.com.br 
Essa importância dada ao falante como sujeito intelectual será contestada pelos construtivistas que acreditam que ele é, antes de tudo, um sujeito social. O que resulta em duas abordagens que, do ponto de vista metodológico aqui apresentado, longe de serem opostas, se completam.

A abordagem de Piaget é baseada em uma Psicologia do Desenvolvimento. Piaget contesta Chomsky com relação ao $\mathrm{LAD}^{4}$. Segundo ele, o ambiente é um elemento fundamental na aquisição da língua. Há um ir e vir entre o meio e o indivíduo e, desse modo, o indivíduo constrói seu conhecimento. Para Piaget, o pensamento autista não verbal em crianças precede sua linguagem egocêntrica antes de ser socializado (PIAGET, 1966).

Quanto a Vygotsky, a criança é considerada, antes de tudo, um ser social e, portanto, sua linguagem é social antes de ser egocêntrica. Assim, o desenvolvimento da criança não pode ser autônomo e independente de seu ambiente. Para ele, as interações desempenham um papel fundamental nesse processo. Desse ponto de vista, o modelo ternário sobrepõe o binário. Destarte, a psicologia que se concentra no indivíduo e na tarefa dá lugar à psicologia que reúne o indivíduo, a tarefa e o outro.

Vygotsky (1997) dá especial atenção aos contextos interativos em que as crianças participam para a aquisição da linguagem. Ele também chega a determinar o papel do adulto e, consequentemente, do professor na organização das aprendizagens, a partir do que ele chama de zona de desenvolvimento proximal, que pode ser compreendida como a diferença fundamental entre o que a criança pode aprender facilmente sem ajuda e o que pode aprender com a intervenção de um mediador.

A ideia fundamental do socioconstrutivismo é que é necessário passar de uma psicologia binária (interação indivíduo-tarefa) para uma psicologia ternária (da interação indivíduo-tarefaalteridade). O desenvolvimento não pode mais ser considerado independente da aprendizagem, ela, por sua vez, não pode ser apenas uma relação privada entre uma criança e um objeto.

\section{Metodologia}

Para a realização deste estudo, foi utilizada a observação participante, dispositivo utilizado na abordagem etnográfica, na qual o pesquisador entra em contato direto com o meio

\footnotetext{
${ }^{4}$ Dispositivo de Aquisição de Linguagem (DAL), em inglês, Language Acquisition Divice.

\section{POLÊM!CA $\mid$ LABORE}

Polêmica - Revista Eletrônica da Uerj - Rua São Francisco Xavier, 524, $1^{\circ}$ andar bloco D, sl.1001 • Tels.: +55 21 2334-4088/4087 • http://www.e-publicacoes.uerj.br/index.php/polemica/index http://www.labore.uerj.br • laboreuerj@yahoo.com.br
} 
que lhe faz a encomenda da pesquisa. Participando da vida do grupo que ele estuda deve permanecer atento a tudo o que lá acontece. Sua atividade de pesquisa é de longo prazo e contínua; nenhum gesto, palavra ou acontecimento são negligenciados. Trata-se de um momento de compartilhamento, trocas e, principalmente, coleta de dados.

Em seu livro sobre microssociologias, Lapassade (1998) traz a seguinte definição de observação participante: "Pesquisa caracterizada por um período de intensa interação entre o pesquisador e os sujeitos, no lugar em que os sujeitos se encontram. Nesse período, os dados são sistematicamente coletados [...] Os observadores se implicam na vida das pessoas. Eles compartilham suas experiências" (BOGDAN; TAYLOR, 1975 apud LAPASSADE, 1998, p. 53).

Com relação a este trabalho, a participação periférica foi adotada por razões práticas e epistemológicas, que se justifica pela necessidade de uma situação de análise, posição defendida por Lapassade (1998). "Participante periférico" é um termo que faz referência a pesquisadores que participam sem estarem totalmente inseridos no dispositivo. Eles não estão no centro das atividades, mas participam de modo que sejam considerados membros sem terem que desempenhar um papel fundamental nas atividades do grupo.

A análise de dados se deu através de um estudo aprofundado do diário de pesquisa ferramenta na qual as experiências de campo foram detalhadamente registradas - e entrevistas que tinham o objetivo de coletar informações que os sujeitos desejavam apresentar.

\section{A produção de diários de bordo: número e regularidade}

A experimentação foi realizada com 102 alunos em uma escola primária em Dakar, Senegal, e durou 8 semanas. Os alunos deveriam entregar um diário a cada semana. Porém, no final, foram recebidos apenas 360 diários dos 816 esperados, uma média de três diários por aluno. O retorno abaixo da média pode ser justificado, em primeiro lugar, devido à liberdade combinada com uma cobrança quase inexistente; os alunos não sentiam uma grande necessidade de escrever seu diário a tempo.

A outra razão é que os próprios observadores recolhiam os diários. Os professores não poderiam desempenhar tal função, uma vez que poderia haver uma mudança na natureza da sua relação com os alunos. Além disso, os estudantes não podiam ser movidos por um sentimento de medo de retaliação em caso de fracasso. Ao longo do tempo, uma melhoria no

\section{POLÊM!CA $\mid$ LABORE}

Polêmica - Revista Eletrônica da Uerj - Rua São Francisco Xavier, 524, $1^{\circ}$ andar bloco D, sl.1001 • Tels.: +55 21 2334-4088/4087 • http://www.e-publicacoes.uerj.br/index.php/polemica/index http://www.labore.uerj.br • laboreuerj@yahoo.com.br 
relacionamento de discentes e docentes foi percebida - o que criou, em alguns momentos, em situações de diversão entre alunos e professores.

O sentido que os alunos atribuíam ao diário também foi posto em questão. De fato, o texto, embora pudesse dar conta da realização do projeto, relata outras atividades e opiniões específicas dos alunos, fato que levanta um questionamento acerca do nível de sensibilização dos professores nesse sentido: os educadores conversaram o suficiente com os alunos sobre a necessidade da entrega de um diário?

Após as observações de campo, notou-se que um apelo foi feito aos alunos para que o fizessem. Isso aconteceu no início do curso, visando explicar a importância do diário. Os professores, então, foram instruídos a, de tempos em tempos, abordar a produção do diário, ao invés de limitar-se ao simples lembrete da necessidade de entrega.

\section{Diversidade de forma e apresentação dos diários: uma liberdade de expressão afirmada}

Um padrão de apresentação não foi exigido dos alunos, devido a isso, eles escreveram os diários à sua maneira. Esse contexto de não exigência e cultura de liberdade fez com que os alunos usassem folhas separadas, pedaços de papel com apenas um lado usado. Há uma série de razões para esses fatos. Na verdade, há uma possibilidade de ter cadernos para fazer suas lições em casa. Entretanto, o uso de uma folha já utilizada reflete os meios precários dos quais estas crianças dispõem. Esses problemas são sempre encontrados pelos alunos por causa da carência em que seus pais se encontram, enfrentando uma notória falta de recursos. Os pais não conseguem satisfazer todas as necessidades de materiais escolares e se contentam em disponibilizar aos seus filhos o mínimo solicitado pelo professor que, geralmente, são cadernos de dever de casa, de redação e composição.

Mas é, também, uma forma das crianças afirmarem a liberdade na produção de diários. Essa liberdade é ilustrada pela forma como determinados textos são apresentados, ou seja, por uma justaposição de frases. Não há, por exemplo, um rigor na pontuação. Isso mostra que eles entraram neste processo de escrita mostrando como eles se sentiam, sem exigirem muito de si - tanto em relação à apresentação quanto ao conteúdo.

Há, ainda, uma diversidade no que diz respeito às regras de ortografia e gramática. Existem erros de todos os tipos. Mesmo sabendo da dificuldade de acompanhar o progresso de cada aluno, é importante observar a existência de diários que foram escritos com poucos ou

\section{POLÊM!CA $\mid$ LABORE}

Polêmica - Revista Eletrônica da Uerj - Rua São Francisco Xavier, 524, $1^{\circ}$ andar bloco D, sl.1001 • Tels.: +55 21 2334-4088/4087 • http://www.e-publicacoes.uerj.br/index.php/polemica/index http://www.labore.uerj.br • laboreuerj@yahoo.com.br 
nenhum erro; no caso de grande parte dos alunos, embora os dados não nos permitissem analisar a sua progressão, produções muito boas foram realizadas.

Os alunos não hesitam em dar lições exaustivas sobre suas informações pessoais, tais como: endereços, idade etc. Isso pode sugerir que, por escrito, os alunos levaram em conta o receptor e tentaram, tanto quanto possível, melhorar a apresentação.

Entretanto, a apresentação citada até então não é uniforme, porque outros alunos usaram outras folhas muito limpas com uma caligrafia bem cuidadosa. Sua forma era comparável aos deveres de casa.

Depois da família e da vizinhança, os alunos fizeram suas críticas aos diferentes componentes da escola. Eles criticaram seus colegas, não podendo deixar de apontar alguns que perturbaram o trabalho do atelier em grupo. Eles denunciaram explicitamente a falta de seriedade de alguns alunos.

Os mestres também foram criticados. Na escola, os professores assumem o papel de mantenedores da ordem, lembrando aos alunos certas regras mínimas de convívio social. No entanto, os alunos não se abstiveram de reprovar os professores. Aqui estão algumas passagens de um aluno lidas em um diário para ilustrar esse fato:

O que me interessa é que os mestres que ficam sentados à sombra de uma árvore, voltem para suas classes depois do recreio. Porque enquanto os mestres ficam sentados à sombra de uma árvore, os alunos estão brigando na sala de aula ou conversando. Um aluno pode se machucar e não teremos condição de cuidar dele. ( $S$ Nd CM1 B 12 anos).

É possível perceber que a criança denuncia determinadas atitudes dos mestres e traz argumentos para fundamentar suas críticas. A oportunidade de se expressar e criticar os professores é dada pelo dispositivo, comprovando, assim, uma certa liberdade de expressão viabilizada pelo diário. Entretanto, o conteúdo dos diários não é apenas um reflexo das críticas e denúncias dos alunos. Também percebe-se manifestações positivas do dispositivo da Pedagogia de Projeto.

Para os alunos, a Pedagogia de Projeto é muito útil, pois permite que eles realizem ações de real importância. O trabalho nos grupos os encantam. Assim, as oficinas são, para eles, o momento de investir no projeto. Eles avaliam que trabalharam bem nos momentos dos ateliês. Há uma autocrítica positiva da parte deles.

\section{POLÊM!CA $\mid$ LABORE}

Polêmica - Revista Eletrônica da Uerj - Rua São Francisco Xavier, 524, $1^{\circ}$ andar bloco D, sl.1001 • Tels.: +55 21 2334-4088/4087 • http://www.e-publicacoes.uerj.br/index.php/polemica/index http://www.labore.uerj.br • laboreuerj@yahoo.com.br 
Os debates em plenário também foram muito apreciados, o que sugere que os alunos precisam desses momentos para trocar, debater, denunciar, mas também se conscientizar sobre certos fatos e fenômenos da sociedade. Isso justifica, mais uma vez, a importância do dispositivo no ensino fundamental. Para os alunos, o projeto é um meio de união.

Nesse sentido, F. B. D., 10 anos, escreve: "Um projeto é um bom negócio porque reúne os alunos. O projeto que tivemos na semana passada sobre as agressões e o lixo em nosso país nos ajudaram muito. Vamos lutar para remover esse lixo."

Os ateliês acontecem sem os professores, mas é útil para eles, mesmo que apenas a título de informação, saber o que acontece nesses momentos. Como tal, o diário de bordo se constituiu como um meio importante de conscientizar os professores. Os alunos costumam falar com frequência sobre as atividades que acontecem nos ateliês, relatando, as vezes, o avanço dos seus projetos. Na mesma linha, foram realizadas adaptações nas diferentes tarefas conferidas a cada membro do grupo. Isso permitiu aos professores, mesmo à distância, acompanhar os diferentes projetos de seus alunos.

No entanto, cabe aqui um questionamento sobre o uso que os professores fizeram desses relatórios. De fato, não foi percebida, nos diferentes momentos de observação, alguma intervenção dos professores. Essa atitude está relacionada a uma certa passividade dos professores ou se deve ao fato de não estarem realmente implicados com o dispositivo? Por ora, é possível dizer, sem dúvida, que os relatórios desempenharam o papel de informação para os professores, contribuindo para a aceitação do dispositivo.

\section{O diário: um vetor de escuta para os jovens}

A recorrência das agressões é motivo de preocupação dos alunos. Visando sua segurança, eles não hesitaram em pedir uma ação do chefe de Estado para intervir nesse flagelo. Para isso, eles o interpelaram e o convidaram explicitamente a ter uma ação não fútil, mas útil. $\mathrm{O}$ fato de se dirigirem a ele mostra tanto o grau de ansiedade em que se encontram como a esperança que nele depositam. É importante dizer que esse tipo de solicitação pode ser considerado um último recurso do qual a criança lança mão como solução definitiva para erradicar a violência. Isso não pode ser feito ignorando a importância da consulta e do diálogo.

Percebeu-se um tipo de trauma para os alunos diante da agressão. De fato, os subúrbios de Dakar, em geral, e as Parcelles Assainies, em particular, costumam ser locais de múltiplas

\section{POLÊM!CA $\mid$ LABORE}

Polêmica - Revista Eletrônica da Uerj - Rua São Francisco Xavier, 524, $1^{\circ}$ andar bloco D, sl.1001 • Tels.: +55 21 2334-4088 / 4087 • http://www.e-publicacoes.uerj.br/index.php/polemica/index http://www.labore.uerj.br・ laboreuerj@yahoo.com.br 
agressões: estupros, roubos, assassinatos, etc. As crianças são tomadas pelo medo, estando muito sensíveis a esse fenômeno. Importante dizer que, no que diz respeito aos agressores, eles acusam, correta ou injustamente, os estrangeiros, neste caso, outros africanos, especialmente os de países limítrofes. Isso reflete um certo nível de informação das crianças. Logo, é preciso avaliar se as informações recebidas são corretas e encontrar uma solução para esse problema.

De qualquer forma, o mestre que recebe o diário se depara com uma forte mensagem que denuncia um medo ameaçador. De fato, ele está sujeito a uma missão outra, levando seus alunos a refletir, pensar e se sensibilizar com o que vivem. Trata-se de uma missão diferente daquela de "encher cabeças". Ele precisa ficar atento a isso. O professor deve voltar ao tema das agressões e iniciar um debate sobre prevenção para tranquilizar a criança e sensibilizar os pais para que cuidem de seus filhos. Esta é uma oportunidade para acabar com os sentimentos de xenofobia, cujos sinais de alerta são visíveis tanto nos debates quanto nos diários das crianças.

Por outro lado, às vezes, as crianças usavam seu diário para confidenciar. Essas confissões estão relacionadas às situações que vivem e, portanto, precisam partilhar com alguém. Eles aproveitaram a oportunidade para falar sobre o desaparecimento de um ente querido ou maus-tratos em casa. Neste sentido, o diário de bordo é uma ferramenta para poder expressar as preocupações, os sofrimentos.

Eles não são apenas meios de expressão do sofrimento; eles também são uma oportunidade de expressar alegrias e sonhos. De fato, seus sonhos em relação ao seu futuro às vezes são realmente explicitados, como o desejo de ter sucesso em seu futuro concurso para o sexto ano ${ }^{5}$ e de obter seus primeiros diplomas.

Outros vão além, projetando-se no futuro, relacionando suas futuras profissões e os bens que gostariam de ter. Os diários são, portanto, oportunidades para a expressão de projetos individuais. Como dito acima, o projeto é entendido como uma meta e não como um programa. Note-se, no entanto, que, durante a produção dos diários, os alunos encontraram dificuldades gramaticais, ortográficas, de conjugação ou simplesmente de expressão.

Deve-se notar que a liberdade de expressão é uma dificuldade muito presente para os alunos. Isso ocorre devido à abordagem de aprendizagem baseada num relacionamento vertical. As ocasiões de escrita são muito raras, os alunos só escrevem quando se trata de fazer uma

\footnotetext{
${ }^{5}$ Sexto ano corresponde ao fim do primário, sendo o primeiro ano do secundário.

\section{POLÊM!CA | LABORË}

Polêmica - Revista Eletrônica da Uerj - Rua São Francisco Xavier, 524, $1^{\circ}$ andar bloco D, sl.1001 • Tels.: +55 21 2334-4088/4087 • http://www.e-publicacoes.uerj.br/index.php/polemica/index http://www.labore.uerj.br • laboreuerj@yahoo.com.br
} 
tarefa. Os tipos de exercícios aos quais eles são submetidos são específicos porque o ensino da língua francesa é fragmentado: a gramática, a ortografia e a conjugação são feitas em lições separadas. Há, além disso, lições de expressão escrita, mas o fato é que existem poucas ocasiões em que essas lições são realmente praticadas. O diário oferece, assim, um momento de expressão e uma oportunidade de escrever livremente

Os diários são uma parte importante do dispositivo; eles são um elo seguro entre o professor e seus alunos. Com o diário, o mestre aprende sobre o que está acontecendo nos ateliês e, em alguns casos, deve fazer ajustes. Sendo o diário uma ferramenta para a expressão de sentimentos íntimos, o professor deverá desenvolver uma escuta atenta, buscando compreender as mensagens dos alunos, analisá-las para entendê-las. Isso permitirá que ele revise seu comportamento em relação aos alunos e, desse modo, aja de maneira eficaz.

\section{Conclusão}

O estado atual da pesquisa em educação no Senegal mostra um uso raro ou mesmo inexistente desse dispositivo pedagógico numa parte das escolas primárias. No entanto, o diário provou sua importância na apropriação e aquisição nos mais diferentes campos do conhecimento. Seu uso oferece muitos benefícios para professores e alunos.

Os estudantes têm no diário uma ferramenta de livre expressão e aprendizagem da língua em seus diferentes aspectos. Além dos meios de comunicação que ele fornece, aprimora as competências linguísticas e constitui uma alavanca fundamental favorável às diferentes dimensões consideradas na aquisição de uma segunda língua. Quanto ao professor, o diário lhe permite conhecer melhor seus alunos e mostra-se uma ferramenta eficaz a serviço de suas diferentes estratégias de ensino da língua.

Portanto, é necessário que todos os atores da escola incentivem iniciativas para melhorar as condições de aprendizagem e ensino. Para tal, o diário é um meio útil e eficaz e qualquer professor pode - e deve - fazer uso regular e frequente dele.

\section{Referências}

BRUNER, J. S. Le développement de l'enfant: savoir-faire, savoir dire. Paris: PUF, 1983.

CHOMSKY, N. Sur la nature et le langage, Marseille: Agone, coll. Banc d'essais, 2011.

CORDER, S. P. Que signifient les erreurs des apprenants? Langages, Paris, v. 14 , n. 57, p. 9-15, mar. 1980.

\section{POLÊM!CA $\mid$ LABORE}

Polêmica - Revista Eletrônica da Uerj - Rua São Francisco Xavier, 524, $1^{\circ}$ andar bloco D, sl.1001 • Tels.: +55 21 2334-4088/4087 • http://www.e-publicacoes.uerj.br/index.php/polemica/index http://www.labore.uerj.br • laboreuerj@yahoo.com.br 
COUËDEL, A. Un dispositif de dynamique de projet et de transformation sociales. Le langage comme enjeu social. Pratiques de formation/analyses, n. 53 - Que doit-on faire des injonctions au projet? Formation permanente. Université de Paris 8, jun. 2007.

COUËDEL, A.; BLONDEAU, N. Une Pédagogie Critique à l'Université. Pédagogie de l'Action et de Transformation Sociale. Pratiques de formation/analyses, Saint Denis, n. 43, p. 27-39, 2002.

FALL, M. La baisse de niveau des élèves en français: mythe ou réalité (le cas du Sénégal). Dakar: Revue Electronique Internationale de Sciences du Langage. Fann SudLangues, 2003. p. 150-161.

KLEIN, W. L'acquisition de langue étrangère. Paris: Armand Colin, 1989.

KRASHEN, S. D. Second Language Acquisition and Second Language Learning. Oxford: Pergamon, 1981.

LAPASSADE, G. Groupes Organisation Institution. 5. ed. Paris: Economica, 2006.

Microsociologie de la vie scolaire. Paris: Economica - Anthropos, 1998.

PIAGET, J. La psychologie de l'enfant. Paris : PUF, 1966.

SKINNER, B. F. Verbal behavior. New York: Appleton-Century-Crofts, 1957.

VALZAN, A. Interdisciplinarité et situations d'apprentissage. Paris: Hachettes Livres, 2003.

VYGOTSKI, L. S. Pensée et Langage. Paris: La Dispute, 1997.

Recebido em: 30/03/2019.

Aceito em: 30/05/2019.

\section{POLÊM!CA $\mid$ LABORE}

Polêmica - Revista Eletrônica da Uerj - Rua São Francisco Xavier, 524, $1^{\circ}$ andar bloco D, sl.1001 • Tels.: +55 21 2334-4088 / 4087 • http://www.e-publicacoes.uerj.br/index.php/polemica/index http://www.labore.uerj.br • laboreuerj@yahoo.com.br 